Article

\title{
Comparative Study on Mixing Behavior of Binary Mixtures of Cocoa Butter/Tristearin (CB/TS) and Cocoa Butter/Coconut Oil (CB/CO)
}

\author{
Bhagyashri L. Joshi *, Birgitta I. Zielbauer ${ }^{\mathbb{D}}$ and Thomas A. Vilgis $(\mathbb{D}$ \\ Max-Planck-Institute for Polymer Research, Ackermannweg 10, 55128 Mainz, Germany; \\ birgitta.zielbauer@gmx.de (B.I.Z.); vilgis@mpip-mainz.mpg.de (T.A.V.) \\ * Correspondence: joshi@mpip-mainz.mpg.de; Tel.: +49-613-137-9149
}

Received: 15 February 2020; Accepted: 7 March 2020; Published: 11 March 2020

check for updates

\begin{abstract}
The comparative study between the mixing behavior of two binary mixtures of cocoa butter (CB)/tristearin (TS) and cocoa butter (CB)/coconut oil (CO) was investigated by using differential scanning calorimetry (DSC). The DSC profile for $\mathrm{CB} / \mathrm{TS}$ blends resulted in a monotectic temperature-concentration ( $\mathrm{T}-\mathrm{X}$ ) phase diagram, whereas a phase diagram of eutectic type was observed for $\mathrm{CB} / \mathrm{CO}$ blends at $65 \mathrm{wt} \%$ of $\mathrm{CO}$ and $35 \mathrm{wt} \% \mathrm{CB}$; this suggests that the eutectic crystal can be formed when the saturated fat (blue $=\mathrm{CO}$ ) is smaller in size compared to monounsaturated fat (orange $=\mathrm{CB}$ ), whereas, for similar and larger size $($ red $=\mathrm{TS}$ ) to $\mathrm{CB}$, phase separation under crystallization is likely to occur (as shown in the graphical abstract). In order to understand the interaction between the binary systems, the profile of the phase diagram was fitted with Bragg-Williams approximation for estimation of the nonideality mixing parameter. Moreover, the morphology of the two different systems by polarized light microscopy (PLM) also depicted the variations in phase behavior by showing a significant change in $\mathrm{CB}$ morphology from spherulitic, grainy to granular and needlelike after the addition of TS and CO, respectively. Our findings emphasize the fundamental understanding of the interaction of bulk fat/fat and fat/oil system.
\end{abstract}

Keywords: cocoa butter; coconut oil; tristearin; mixing behavior; morphology; phase diagram; DSC; PLM

\section{Introduction}

The mixing of fats and oils is widely used in food, pharmaceutical and cosmetic applications [1-3]. Likewise, in some applications, the lipid system is one of the main constituents, which defines the ultimate product quality and storage life [4,5]; therefore, the interaction between different fats and oils in mixtures of various compositions is important to design the desired product having specified physicochemical properties. Apart from these application aspects, studies of fat and oil blends offer deep insight into the fundamental aspects of the crystallization of molecules with molecularly controlled complexity.

Fats and oils mainly consist of mixtures of triacylglycerols (TAGs), having three fatty acids attached to the glycerol backbone, hence, their physicochemical properties depend on the sn-position of these fatty acids to the glycerol backbone and their degree of saturation [6]. This specific structure of the TAGs allows the direct observation of crystallization phenomena due to the slow time scales expressed in significant slow crystallization rates, which are controlled by the length of the fatty acids and the saturation degree. Many relevant physical quantities can thus be directly observed.

In the case of TAGs, typically three $\left(\alpha, \beta^{\prime}\right.$ and $\left.\beta\right)$ different polymorphs form upon cooling [7]; therefore, depending on the packing density of the TAGs (loosely packed or densely packed) the 
physicochemical properties of fat crystals get affected [8]. It is necessary, therefore, to understand the interactions inside binary systems in liquid and solid-states for developing various applications. Although the mixing behavior of various pure TAGs has been explored very well $[9,10]$ and their phase diagram has also been studied in detail, there are only a few studies that explain the thermodynamic analysis of the mixing behavior in bulk systems [11]. Therefore, in this study, we have considered two sets of blends cocoa butter (CB)/tristearin (TS) and cocoa butter (CB)/coconut oil (CO) to understand the interaction between these mixtures on a broad concentration spectrum.

CB consists of mainly monounsaturated symmetrical TAGs, namely POP (1,3-dipalmitoyl-2-oleoyl glycerol), POS (1,3-palmitoyl-stearoyl-2-oleoyl glycerol) and SOS (1,3-distearoyl-2-oleoyl glycerol); where $\mathrm{P}=$ palmitic acid, $\mathrm{O}=$ oleic acid and $\mathrm{S}=$ stearic acid (approximately $17 \%$ of POP, $37 \%$ of POS and $27 \%$ of SOS) [12]. The remaining part consists of mixtures of monounsaturated and polyunsaturated TAGs, as well as traces of polyphenols and free fatty acids. CB crystallizes into six $\left(\gamma, \alpha, \beta_{2}{ }^{\prime}, \beta_{1}{ }^{\prime}\right.$, $\beta_{2}$ and $\beta_{1}$ ) different polymorphs in which melting temperature and their stability increases from $\gamma$ to $\beta_{1}[13]$.

TS is a monosaturated TAG composed of three stearic acids (SSS) with 18 carbon atoms each, which crystallizes into three polymorphs namely, $\alpha$ (less stable), $\beta^{\prime}$ (metastable) and $\beta$ (highly stable) with melting temperatures of $54{ }^{\circ} \mathrm{C}, 65^{\circ} \mathrm{C}$ and $72.5^{\circ} \mathrm{C}$, respectively [14]. Previous studies were only carried out on the addition of a low concentration of TS to CB. For instance, the study on the effect of $1 \mathrm{wt} \%$ and $5 \mathrm{wt} \%$ of TS on the crystallization of CB showed the increase in onset temperature of the mixture and the polymorphic transition from $\beta^{\prime}$ to $\beta$ was also delayed [15]. However, systematic investigations on higher percentages have not yet been explored; hence, in our present study, the selection of such a combination was used. Interestingly, TS is also present in CB as a minor component [12], and hence, it was intriguing to observe the possible changes that would occur after the blending of TS in a higher percentage with CB.

It has been shown that $\mathrm{CO}$ can be used as a cocoa butter substitute $[16,17]$ as it consists of a high amount of lauric acid ( 40\%) followed by myristic and palmitic acid [18]. There are a wide range of research studies that have been done previously on mixing behavior and crystallization of $\mathrm{CB}$ with lauric fats [19-22]. However, the effect of isothermal and dynamic crystallization processes on physicochemical properties and morphological changes of a broad range of $\mathrm{CB} / \mathrm{CO}$ blends has not been explored yet. We believe that following this approach will help to determine the exact eutectic point of $\mathrm{CB} / \mathrm{CO}$ blends.

The mixing ratios of a binary system of fat-fat and fat-oil blends determine their solid-liquid phase diagram. The solid-liquid phase diagram helps to understand the differences in the thermal properties of blends when mixed together in different ratios. There are typically four different phase diagrams identified by Timms [23]-(1) monotectic continuous solid solutions, (2) eutectic systems, (3) monotectic partial solid solutions, and (4) peritectic systems. Interestingly, in our study, CB/TS and $\mathrm{CB} / \mathrm{CO}$ blends showed monotectic and eutectic mixing behavior, respectively. The model schematic is shown in Figure 1 for typical monotectic and eutectic phase diagrams.

However, in the case of pure saturated fat, one may have to consider either melt-mediated or solid-liquid-solid (S-L-S) transition or solid-solid (S-S) transition while constructing the solid-liquid phase diagram. Melt-mediated, also known as S-L-S transition, can be explained by the transformation of one polymorph into another via melting. During heating, one polymorph melts and recrystallizes into another polymorph. On the contrary, S-S transition is the transformation of one polymorph into another form in solid state [24]. Understanding such transformations could help to design the technological processes during fat crystallization in food applications.

Altogether we analyzed the thermal properties of different blends of $\mathrm{CB} / \mathrm{TS}$ and $\mathrm{CB} / \mathrm{CO}$ mixtures by using isothermal and dynamic crystallization methods. The changes in thermal properties and morphology of these blends were measured by using differential scanning calorimetry (DSC) and polarized light microscopy (PLM), respectively. From the DSC results, the phase diagram was constructed. The thermodynamic analysis of these phase diagrams helped to understand the interaction 
between $\mathrm{CB} / \mathrm{TS}$ and $\mathrm{CB} / \mathrm{CO}$ in a solid and liquid state. Therefore, our study sheds a light on the applied point of view while understanding the basics of these interactions. Ultimately, it will help in future for comprehending the correlation of differences in mouthfeel, based on usage of different concentrations of the mixtures of these oil and fat blends.

(a)
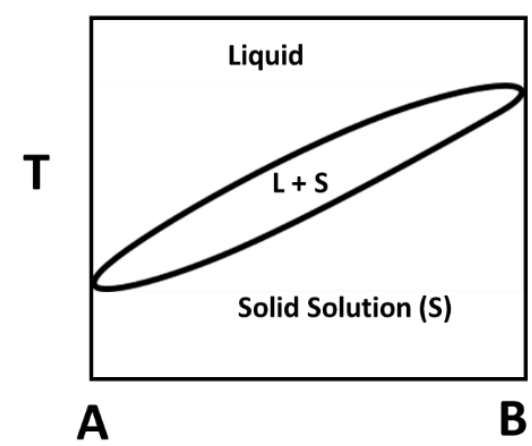

(b)

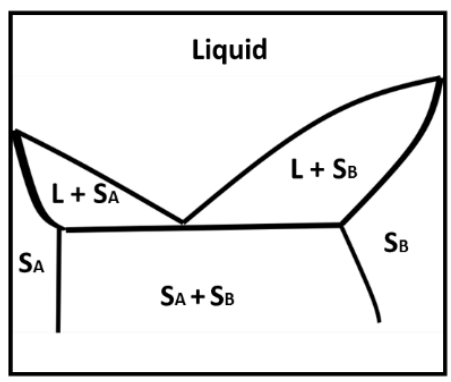

B

Figure 1. Model schematic of two types of phase diagram in binary mixtures of triacylglycerols (TAGs); (a) monotectic, continuous solid solution, (b) eutectic phase behavior (redrawn from [23] with copyright permission).

\section{Materials and Methods}

\subsection{Materials and Blends Preparation}

To study thermal properties and morphological changes in the mixtures, CB (Carl Roth GmbH + Co. KG, Karlsruhe, Germany), TS and CO (Sigma-Aldrich GmbH, Steinheim, Germany) were used as a model system. The blends were prepared at ratios from $100 w / w \%$ to $0 w / w \%$ in steps of $10 \mathrm{wt} \%$ for each experiment. For the preparation of samples, CB and another fat were melted individually and then added together; this mixture was further heated for another $30 \mathrm{~min}$ while stirring. Later, the mixture was transferred into a preheated sample holder (aluminum crucible and microscopic glass slide for DSC and PLM, respectively). Afterward, the sample was heated again for $15 \mathrm{~min}$ in the oven to eliminate the crystallization due to temperature difference, while transferring the sample. The sample was then stored for $24 \mathrm{~h}$ at $22{ }^{\circ} \mathrm{C}$ in a constant climate chamber (Binder KMF115) with $0 \%$ relative humidity. The analysis of these samples was carried out by using DSC and PLM for thermal analysis and morphological studies, respectively.

\subsection{Compositional Analysis of $C B$ and $C O$}

The fatty acid analysis of CB and CO was determined by GC-FID commercially (Company A, name not mentioned due to confidentiality agreement) and TAG composition of $\mathrm{CB}$ was resolved by HPLC analysis commercially (Eurofins Analytik GmbH, Hamburg, Germany).

\subsection{Thermal Analysis by Differential Scanning Calorimetry (DSC)}

DSC was used for the thermal analysis of the mixtures. The blends were prepared as explained in Section 2.1 and then stored in the aluminum crucible ( $20 \mathrm{mg}$ sample) for $24 \mathrm{~h}$ at $22{ }^{\circ} \mathrm{C}$ prior to DSC (Mettler Toledo DSC3+/700/453) measurements. An empty $100 \mu \mathrm{L}$ aluminum pan was considered as a reference cell. Liquid nitrogen was used for cooling with a rate of $30 \mathrm{~mL} / \mathrm{minute}$. The experiment was performed in four segments in order to study the thermal properties of fat/oil blends crystallized via isothermal and dynamic processes. The sample, which was crystallized by the isothermal process at $22{ }^{\circ} \mathrm{C}$, was heated first to $90{ }^{\circ} \mathrm{C}$ in order to study the crystal formation after $24 \mathrm{~h}$ and kept for $20 \mathrm{~min}$ to erase all crystal memory. Later, the sample was cooled down to $-50^{\circ} \mathrm{C}$ and immediately heated to $90{ }^{\circ} \mathrm{C}$ in the next segment. In our study, we have considered the peak temperature as 
the melting/crystallization temperature of the system, and the onset and offset point denotes the start and end of the thermal process. For a better understanding of the DSC profile, the heat flow parameter was increased in steps of $0.2 \mathrm{~W} / \mathrm{g}$ in each sample measurement while plotting in Section 3.2.1. All thermograms were plotted with respect to weight percent $\left(\mathrm{X}_{\mathrm{CB}}\right)$ of $\mathrm{CB}$ in the blends. The analysis was performed in triplicate, and the evaluation of the graphs was carried out in STARe software.

\subsection{Thermodynamic Analysis of Pseudophase Diagrams}

Based on DSC results, we generated the pseudophase diagram for $\mathrm{CB} / \mathrm{TS}$ and $\mathrm{CB} / \mathrm{CO}$ blends. The reason to term these binary phase diagrams as 'pseudo' is that each component of the 'blended' $\mathrm{CB}$ and $\mathrm{CO}$ consists already of broader mixtures of TAGs, which makes them a bulk system and not a pure single-component system. However, in our case and according to the data obtained, we assume $\mathrm{CB}$ and $\mathrm{CO}$ as a one constituent system, and therefore our diagram reflects the binary phase diagram.

The phase behavior of binary systems has been explained in detail for fatty acid mixture and phospholipids by using ideal mixing and nonideality of mixing [25-27]. For ideal mixing behavior, the Hildebrand equation is used to simulate the liquidus line derived from the phase diagram $[26,28]$. According to this model, the liquidus line of a binary mixture of components $\mathrm{A}$ and $\mathrm{B}$ being completely immiscible in the solid phase, is given by either Equation (1) or (2), depending on their composition range [28,29].

$$
\begin{aligned}
& \ln x_{A}=-\frac{\Delta H_{A}}{R}\left(\frac{1}{T}-\frac{1}{T_{A}}\right) \\
& \ln x_{B}=-\frac{\Delta H_{B}}{R}\left(\frac{1}{T}-\frac{1}{T_{B}}\right)
\end{aligned}
$$

where $R$ is the gas constant, $x_{A}, \Delta H_{A}, T_{A}$ represent, mole fraction, molar latent heat of fusion and melting point of A, respectively, similarly, $x_{B}, \Delta H_{B}, T_{B}$ for component $\mathrm{B}$.

On the other hand, the nonideality of mixing is described by the Bragg-Williams approximation. This equation is based on the nonideality parameter $\chi$, which explains the interaction between two components in liquid and solid-state. $\chi$ is the energy difference between the pair $(\mathrm{A}-\mathrm{B})$ and the average of $(\mathrm{A}-\mathrm{A})$ and $(\mathrm{B}-\mathrm{B})$ pairs and is described as

$$
\chi=z\left(u_{A B}-\frac{\left(u_{A A}+u_{B B}\right)}{2}\right)
$$

where $z$ is the coordination number, i.e., the number of nearest-neighbor molecules of the individual molecules and $u_{A B}, u_{A A}$ and $u_{B B}$ are the binary interaction energy of the pair $\mathrm{A}-\mathrm{B}$ and pair $\mathrm{A}-\mathrm{A}$ and $\mathrm{B}-\mathrm{B}$, which describes the interaction of either component in liquid or a solid phase. In principle, these energies reflect the point-like pseudo interaction between monomers in polymer mixing theory [30], however, in case of mixed TAGs, the monomers (fatty acids) are not of similar origin hence, these interactions could be either between the methyl end group, aliphatic carbon-carbon chain length or from esterified glycerol part of different TAGs. Therefore, these fatty acids cannot be considered as point-like in the lattice model for understanding the interaction. Thus, $u_{A B}, u_{A A}$ and $u_{B B}$ would be assumed as the combination of interactions between three different parts of TAG, as explained above.

For ideal mixing, the difference is zero, therefore, $\chi$ is zero. Positive $\chi$ indicates the clustering of similar molecules, which beyond some critical value leads to phase separation into phases of different composition. Negative $\chi$ denotes a tendency for order [26]. The two equations which are shown below represents the Bragg-Williams approximation of nonideality;

$$
\begin{aligned}
& \ln x_{A}+\chi\left(1-X_{A}\right)^{2} / R T=-\frac{\Delta H_{A}}{R}\left(\frac{1}{T}-\frac{1}{T_{A}}\right) \\
& \ln x_{B}+\chi\left(1-X_{B}\right)^{2} / R T=-\frac{\Delta H_{B}}{R}\left(\frac{1}{T}-\frac{1}{T_{B}}\right)
\end{aligned}
$$


For monotectic behavior, either of the two equations is simulated to give the liquidus line, whereas, for the eutectic mixture, for composition range between $x_{E} \leq x_{A} \leq 1$ Equation (4) is used and for $0 \leq x_{A} \leq x_{E}$ Equation (5) is used.

In our study, we have considered $A$ and $B$ components as TS and CB in CB/TS blends, respectively, and $\mathrm{CB}$ as $\mathrm{A}$ and $\mathrm{CO}$ as $\mathrm{B}$ in $\mathrm{CB} / \mathrm{CO}$ blends. For calculation of the mole fraction of $\mathrm{CB}$ and $\mathrm{CO}$, the average molecular weight was calculated based on the TAG profile of both lipids. The TAG profile for CB was evaluated as given in Section 2.2, and for CO the TAG profile was taken from the study of Toro-Vazquez group study on physicochemical properties of trans-free and partially hydrogenated soybean oil [31]. The calculated average molecular weight of CB, CO and TS were $822 \mathrm{~g} / \mathrm{mol}, 627 \mathrm{~g} / \mathrm{mol}$ and $890 \mathrm{~g} / \mathrm{mol}$, respectively. For fitting these equations to the phase diagram derived from DSC, OriginPro 9.1 software (OriginLab Corporation, Northampton, MA, USA) was used.

\subsection{Morphological Studies by Polarized Light Microscopy (PLM)}

The morphology of the samples was studied by PLM (Zeiss Scope, A1 Pol). A $10 \mu \mathrm{L}$ of sample was pipetted to a preheated microscope slide, and carefully, the coverslip was placed on the top of the molten sample to avoid air bubble formation. These slides were stored at $22{ }^{\circ} \mathrm{C}$ for $24 \mathrm{~h}$ prior to PLM. The pictures were captured after $24 \mathrm{~h}$ for each sample, and the result of dynamic crystallization was studied by using a temperature profile similar to the one used in DSC analysis. The heating and cooling were attained by a Peltier plate setup (Linkam, model PE120). The sample was heated to $90{ }^{\circ} \mathrm{C}$ with a $2 \mathrm{~K} /$ minute rate and kept isothermally for $60 \mathrm{~min}$ to erase the crystal memory. As the heating systems are different in DSC and PLM, longer isothermal heating time at $90^{\circ} \mathrm{C}$ was used as compared to DSC. Afterward, the sample was cooled down to $10{ }^{\circ} \mathrm{C}$ with a $2 \mathrm{~K} /$ minute rate, and at this temperature, the pictures were captured by using objective $20 \times$. All measurements were carried out in duplicate.

\section{Results and Discussions}

\subsection{Compositional Analysis of $\mathrm{CB}$ and $\mathrm{CO}$}

The fatty acid (FA) analysis of $\mathrm{CB}$ and $\mathrm{CO}$ is shown in Table 1. The results depict that $\mathrm{CB}$ consists of long-chain saturated FA ranging from (C18:0)-(C24:0). The concentration of stearic acid (C18:0), arachidic acid (C20:0), behenic acid (C22:0) and lignoceric acid (C24:0) are significantly high as compared to other studies [32,33]. As a result, this kind of CB could melt at a higher temperature. Thus, while preparing the samples, the temperature used was $90{ }^{\circ} \mathrm{C}$, to ensure complete melting. The concentration of palmitic acid (25.32 wt \%), stearic acid (36.74 wt \%) and oleic acid $(32.48 \mathrm{wt} \%)$ in $\mathrm{CB}$ is highest with respect to other FAs present in $\mathrm{CB}$, which is in agreement with other studies [34-36]. In contrast with $\mathrm{CB}$, the concentration of $(\mathrm{C} 18: 0)-(\mathrm{C} 24: 0)$ was very low in $\mathrm{CO}$, and it mainly consisted of small and medium-chain FA ranging from (C8:0)-(C16:0), in which lauric acid (42.78\%) and myristic acid $(17.64 \%)$ were present in higher concentration. Although CO was found to contain a high amount of saturated fatty acids, oleic acid $(9.23 \%)$ and linoleic acid $(2.99 \%)$ were also detected in a significant amount. This mixture of short, medium and long-chain fatty acids and their sn-position explains the different physical, thermal and mechanical properties of fats [6].

The TAG composition of CB was determined by HPLC and is shown in Table 2. However, the TAG composition did not show the presence of arachidic acid (C20:0), behenic acid (C22:0) and lignoceric acid (C24:0) in terms of TAGs. Unfortunately, we could only succeed to separate $~ 95 \%$ of TAGs; therefore, it was difficult to conclude whether these long-chain fatty acids were present in TAG, diacylglycerol (DAG), monoacylglycerol (MAG) or in terms of free fatty acid. Thus, the mixtures of different TAG, DAG, MA and FA in CB form were a complicated system by itself. 
Table 1. Fatty acid composition of cocoa butter (CB) and coconut oil (CO).

\begin{tabular}{|c|c|c|}
\hline Fatty Acid & Cocoa Butter (Weight \%) & Coconut Oil (Weight \%) \\
\hline Caproic acid (C6:0) & - & 0.72 \\
\hline Caprylic acid (C8:0) & - & 7.75 \\
\hline Capric acid (C10:0) & - & 5.64 \\
\hline Lauric acid (C12:0) & - & 42.78 \\
\hline Myristic acid (C14:0) & 0.09 & 17.64 \\
\hline Palmitic acid (C16:0) & 25.32 & 9.61 \\
\hline Palmitoleic acid (C16:1 $\omega 7 \mathrm{c})$ & 0.24 & - \\
\hline Heptadecanoic acid (C17:0) & 0.21 & - \\
\hline Stearic acid (C18:0) & 36.74 & 2.87 \\
\hline Octadecenoic acid (C18:1-trans) & 0.02 & - \\
\hline Oleic acid $(\mathrm{C} 18: 1 \omega 9 \mathrm{c})$ & 32.48 & 9.23 \\
\hline Linoleic acid $(\mathrm{C} 18: 2 \omega 6 \mathrm{c})$ & 2.88 & 2.99 \\
\hline Octadecadienoic acid(C18:2w6-trans) & 0.02 & - \\
\hline alpha Linolenic acid (C18:3w3c) & 0.17 & 0.3 \\
\hline Arachidic acid (C20:0) & 1.09 & 0.1 \\
\hline cis-11-Eicosenoic acid (C20:1w9c) & - & 0.09 \\
\hline Behenic acid $(\mathrm{C} 22: 0)$ & 0.18 & - \\
\hline Lignoceric acid (C24:0) & 0.1 & - \\
\hline Saturated fatty acids & 63.73 & 87.11 \\
\hline Monounsaturated fatty acids & 33.07 & 9.53 \\
\hline Polyunsaturated fatty acids & 3.05 & 3.29 \\
\hline Trans fatty acids & 0.04 & $<0.01$ \\
\hline omega- 3 fatty acids & 0.17 & 0.3 \\
\hline omega- 6 fatty acids & 2.88 & 2.99 \\
\hline
\end{tabular}

Table 2. TAG composition of $\mathrm{CB}$.

\begin{tabular}{cccc}
\hline $\begin{array}{c}\text { TAGs in } \\
\text { CB }\end{array}$ & Conc. (wt \%) & TAGs in CB & Conc. (wt \%) \\
\hline PPP & 0.1 & PLL & 0.4 \\
MOP & 0.1 & SSS & 0.3 \\
PPS & 0.5 & SOS & 26.5 \\
POP & 16.7 & OOS & 2.2 \\
PLP & 1.8 & OOO & 0.2 \\
PSS & 0.6 & SLO & 0.3 \\
POS & 39.8 & OLO & 0.1 \\
POO & 1.7 & SLL & 0.2 \\
PLS & 3.4 & LLO & $<0.1$ \\
PLO & 0.3 & LLL & $<0.1$ \\
\hline palmitic acid; $M=$ myristic acid; $\mathrm{O}=$ oleic acid; $\mathrm{S}=$ stearic acid; $\mathrm{L}=$ linoleic acid.
\end{tabular}

Therefore, the thermal properties of fats and oils mainly depend on the composition of the individual fat and $\mathrm{wt} \%$ in the mixture. For instance, blends of $\mathrm{CB} / \mathrm{canola}$ oil and $\mathrm{CB} /$ soybean oil show different characteristics, as canola oil consists of mainly OOO, LOO and OLnO, whereas in soybean oil LLL, LLO and LOO are present (where $\mathrm{O}=$ oleic acid; $\mathrm{L}=$ linoleic acid; $\mathrm{Ln}=$ linolenic acid) [37].

\subsection{Characterization of Thermal Properties by Using DSC}

\subsection{1. $\mathrm{CB} / \mathrm{TS}$ Blends Characterization}

Figure 2 shows DSC thermograms for three different segments of CB/TS mixtures. After storage of the sample at $22{ }^{\circ} \mathrm{C}$ for $24 \mathrm{~h}$, the melting thermogram (Figure 2a) was performed for studying the effect on the melting behavior of blends after isothermal crystallization. CB/TS showed a linear trend with respect to change in concentration of fats. In the case of pure $C B$, two endothermic peaks 
occurred during the melting process, which can be ascribed to the melting of two polymorphs, form IV $\left(30.85^{\circ} \mathrm{C}\right)$ and form $\mathrm{V}\left(33.6^{\circ} \mathrm{C}\right)$ [13]. Similarly, in the case of pure TS, one endothermic peak at $46.8^{\circ} \mathrm{C}$ (indicated by $\alpha$ melt arrow) and another at $61.7^{\circ} \mathrm{C}\left(\mathrm{P}_{\mathrm{TS}}\right)$ were observed. However, according to a study by Windbergs' group [14], onset temperatures of $54{ }^{\circ} \mathrm{C}$ and $63{ }^{\circ} \mathrm{C}$ represent $\alpha$ and $\beta^{\prime}$ polymorphic forms. The difference in the melting temperatures between our work and Windbergs' study might correspond to the difference in sample preparation technique.
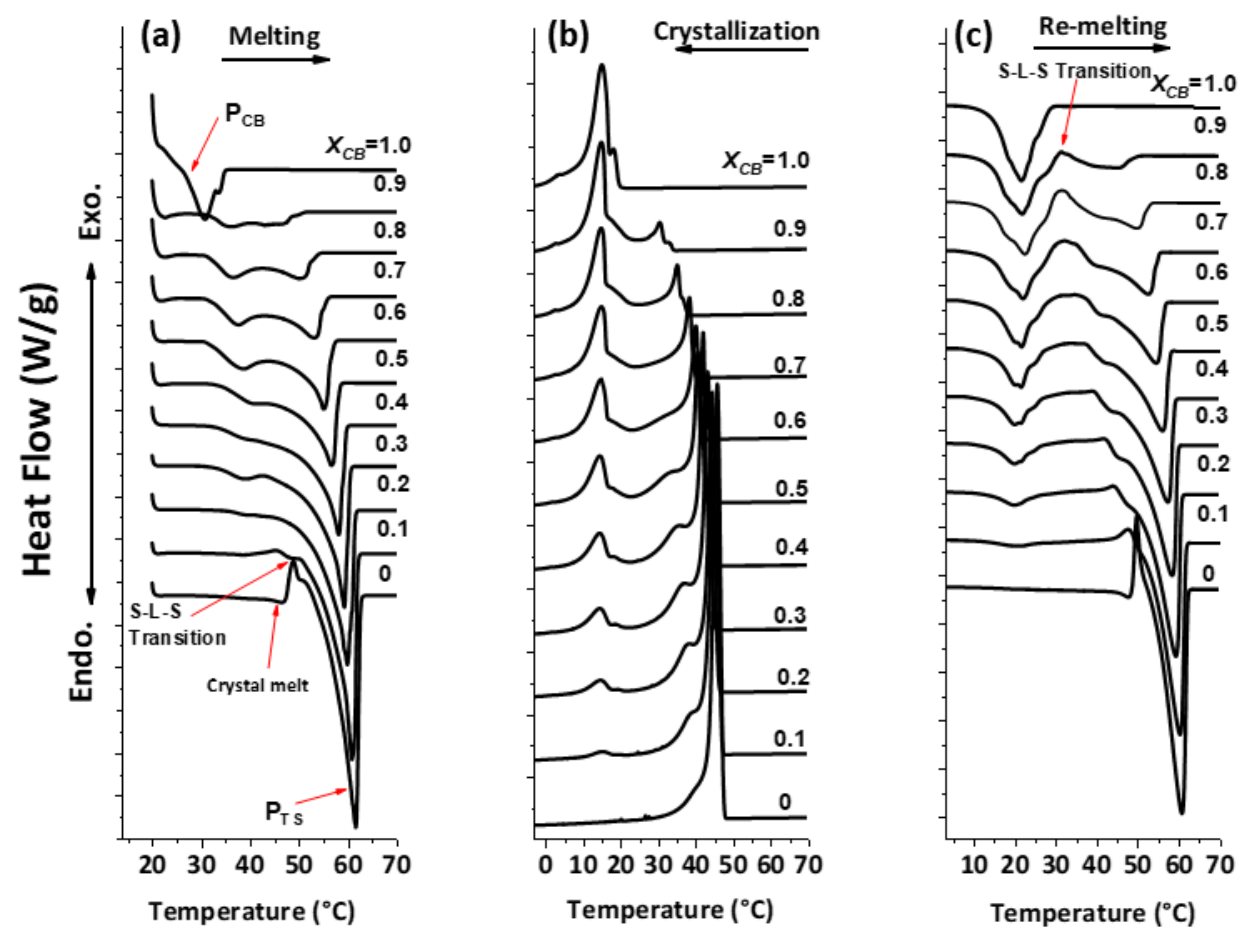

Figure 2. Differential scanning calorimetry (DSC) analysis of cocoa butter (CB)/tristearin (TS) (CB/TS) blends. (a) Melting process after crystallization for $24 \mathrm{~h}$ at $22{ }^{\circ} \mathrm{C}$. The arrows indicate the peak of CB (PCB), the peak representing TS (PTS) and $\alpha$ polymorph melting. (b) Dynamic crystallization from $90{ }^{\circ} \mathrm{C}$ to $-50{ }^{\circ} \mathrm{C}$. (c) Remelting of crystals formed in segment (b). Arrow indicates the S-L-S (Solid-Liquid-Solid) transition.

For blends, after the addition of TS to pure $\mathrm{CB}$, the peak shifted towards a higher temperature, and the peak area increased accordingly as the concentration of TS increased. Another observation, in the pure TS curve, an exothermic peak was observed during melting (indicated with a red arrow in Figure 2a). This phenomenon occurs due to S-L-S or melt-mediated transition in TS. Firstly, one crystal form was melted at $46.8^{\circ} \mathrm{C}$ and recrystallized into another crystal form at $48^{\circ} \mathrm{C}$, which was melted immediately. Therefore, an observable S-L-S transition instead of S-S transition occurs.

Similarly, with DSC and X-ray diffraction, the study of Lavigne and group proved the hypothesis of $\alpha$ to $\beta$ phase transition in TS was S-L-S transition type, as the $\beta$ phase occurred from a melt of $\alpha$ and not directly from solid $\alpha$ [38]. The S-S transformation from vertical $\alpha$ form to $\beta^{\prime}$ could be due to the collapse of hydrocarbon chains or from bending of each molecule in the glycerol region [39]; however, the reason for S-L-S transformation is still yet to understand.

The next segment (in Figure $2 b$ ) was designed to observe the effect of dynamic crystallization on the individual fats and their respective blends. The controlled cooling process was achieved by this segment led to the formation of different crystal forms from the isothermal crystallization for $24 \mathrm{~h}$. The crystallization exotherms for all samples are shown in Figure $2 b$. Pure $C B\left(X_{C B}=1\right)$ crystallized according to the composition of TAGs present in the $\mathrm{CB}$. The cocrystallization of the high melting fraction (HMF), a medium melting fraction (MMF) and a low melting fraction (LMF) took place. Likewise, pure TS crystallized into one crystal form, having a higher melting point and showing 
a sharp peak at $45^{\circ} \mathrm{C}$, along with the shoulder peak of another polymorph. The blends produced two exothermic peaks, in which $\mathrm{P}_{\mathrm{TS}}$ represented TS, and $\mathrm{P}_{\mathrm{CB}}$ indicated $\mathrm{CB}$. Furthermore, $\mathrm{P}_{\mathrm{TS}}$ shifted towards lower temperature after the addition of $\mathrm{CB}$ into it, and the area of peak decreased accordingly. Whereas, for $\mathrm{P}_{\mathrm{CB}}$, only the peak area decreased after the addition of TS, but not specific change in the crystallization temperature of $\mathrm{CB}$ was observed.

For determination of the $\Delta H$ value in crystallization and melting segments of CB/TS blends, $\mathrm{P}_{\mathrm{CB}}$ peaks were taken as reference peaks, as there was no specific peak shift. For the crystallization process, the range from $90{ }^{\circ} \mathrm{C}$ to $24{ }^{\circ} \mathrm{C}$ was considered for $\mathrm{P}_{\mathrm{TS}}$, and below for $\mathrm{CB}$, whereas, for the remelting process, first endothermic peak area for $\mathrm{CB}$, exothermic peak for solid-liquid-solid transition and second endothermic peak for TS (refer to supplementary Figure S1).

The remelting procedure was carried out to determine the melting profile of crystals that formed during the crystallization process (segment 2) with a heating rate of $2 \mathrm{~K} /$ minute. The melting endotherms detected by DSC are shown in Figure 2c. Similarly, as in segment 2, $\mathrm{P}_{\mathrm{TS}}$ represents endotherm of TS and $\mathrm{P}_{\mathrm{CB}}$ represents $\mathrm{CB}$. In the case of pure $\mathrm{CB}$, DSC detected one sharp peak along with shoulder peaks, which ascribed that mixture of different melting fractions, were melted (from LMF to HMF). In the case of TS, two melting fractions were formed, similarly, as of first melting (segment 1 in Figure 2a), only the peak temperature of higher melting fractions was slightly shifted from $61.4^{\circ} \mathrm{C}$ to $60.97^{\circ} \mathrm{C}$, respectively. Hence, from the endotherms of all the blends and the melting temperature (MT) of TS decreased after the addition of CB, similar to segment 1 . However, the exothermic peak (S-L-S transition) did not vanish completely, even after the addition of CB. For the evaluation of these endotherms, the temperature limit was selected as: below temperature $31.06^{\circ} \mathrm{C}$, the area was considered as $\mathrm{CB}$, and above temperature $33.4^{\circ} \mathrm{C}$ for TS. Figure 3 shows the crystallization, melting and S-L-S transition enthalpy change against $\mathrm{X}_{\mathrm{CB}} . \Delta H$ for crystallization and melting exponentially decreased as $\mathrm{CB}$ increased, whereas, for $\mathrm{CB}$, both processes showed a linear decrease in enthalpy as the concentration of TS increased. In the case of S-L-S transition from the remelting method, the enthalpy change was almost constant throughout the composition of TS. This result indicated that $\Delta H$ for S-L-S transition was independent of the composition (see supplementary data Section 2).

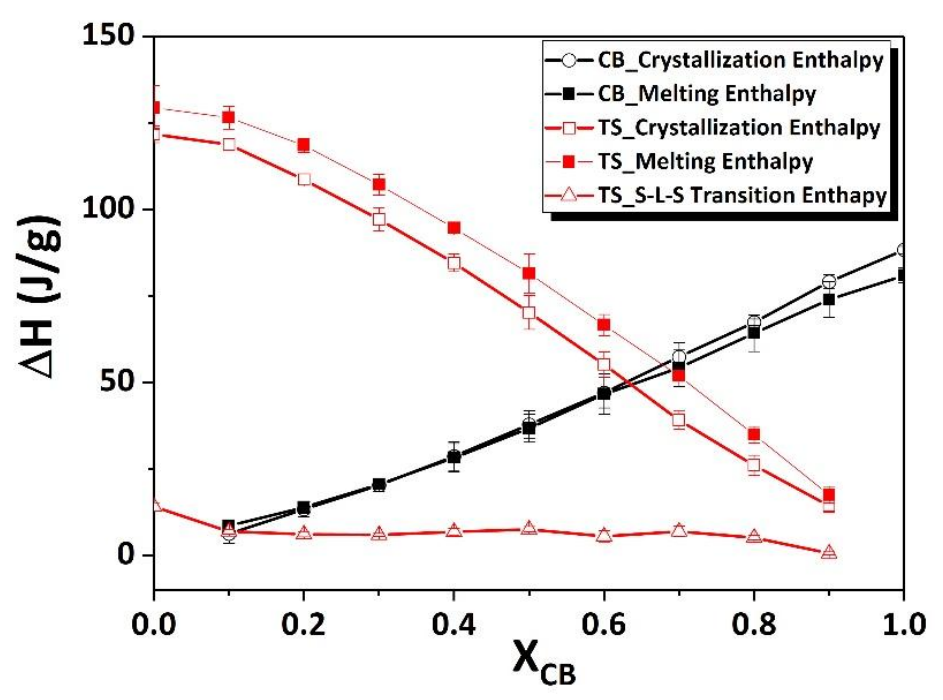

Figure 3. Enthalpy change of $\mathrm{CB}$ and TS during the crystallization and remelting process with respect to weight $\%$ of CB. black open square = crystallization, black filled square = remelting, red open square $=$ crystallization, red filled square = remelting, open triangle = enthalpy change in S-L-S transition while remelting.

\subsubsection{DSC Results of $\mathrm{CB} / \mathrm{CO}$ Mixtures}

Figure $4 \mathrm{a}-\mathrm{c}$ show the DSC results of melting after $24 \mathrm{~h}$ at $22{ }^{\circ} \mathrm{C}$, crystallization and remelting thermograms of $\mathrm{CB} / \mathrm{CO}$ blends. In the first segment of melting, only the samples with $\mathrm{X}_{\mathrm{CB}}$ of 1.0, 
0.90 and 0.80 showed the melting from the crystals that were formed during $24 \mathrm{~h}$ of crystallization (Figure 4a). This behavior ascribed that $\mathrm{CO}$ was inhibiting the crystallization process of $\mathrm{CB}$ when added at more than $10 \mathrm{wt} \%$. Similar results were obtained from NMR results studying the crystallization kinetics of CB and CO blends over a period of $24 \mathrm{~h}$ (refer to supplementary Figure S2). Likewise, the study [19] of crystallization behavior and kinetics of chocolate with lauric fat showed that at different temperature ranges, the solid fat content decreased after the addition of $10 \%, 20 \%$ and $30 \%$ of CO, palm kernel oil and fractionated palm kernel oil, respectively. This decrease in solid fat content can be explained by the TAG composition in both the fats. CO contains a mixture of mixed and short-chained saturated TAGs, whereas CB is a mixture of long-chain monounsaturated TAGs. Therefore, the packing ability is compromised between these fats together, and so eventually, the compatibility is reduced.

(a)

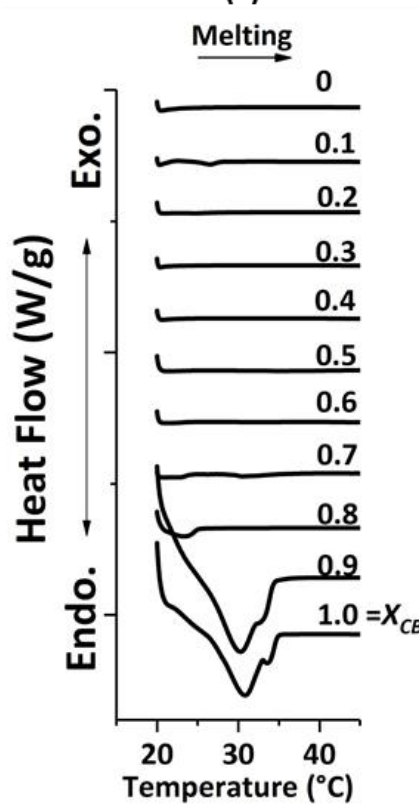

(b)

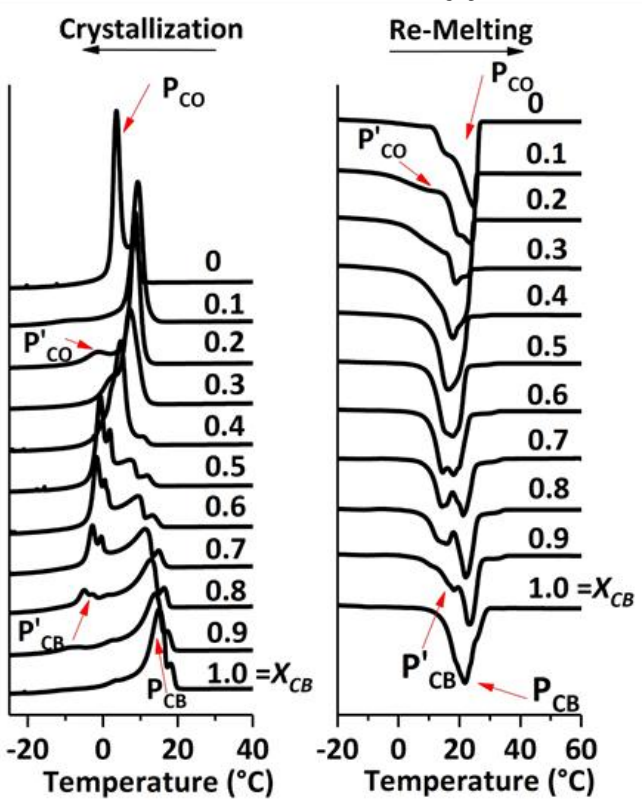

Figure 4. DSC analysis of $\mathrm{CB} / \mathrm{CO}$ blends. (a) Melting process after crystallization for $24 \mathrm{~h}$ at $22^{\circ} \mathrm{C}$. (b) Dynamic crystallization from $90{ }^{\circ} \mathrm{C}$ to $-50{ }^{\circ} \mathrm{C}$. (c) Remelting of crystals formed in segment (b). The arrows indicate the peak of $\mathrm{CB}\left(\mathrm{P}_{\mathrm{CB}}\right)$, the peak representing $\mathrm{CO}\left(\mathrm{P}_{\mathrm{CO}}\right)$, shoulder peaks appearing after the addition of $\mathrm{CO}$ in $\mathrm{CB}\left(\mathrm{P}^{\prime}{ }_{\mathrm{CB}}\right)$ and shoulder peaks appearing after the addition of $\mathrm{CB}$ in $\mathrm{CO}$ $\left(\mathrm{P}^{\prime} \mathrm{CO}\right)$.

The results of crystallization are shown in Figure $4 \mathrm{~b} . \mathrm{P}_{\mathrm{CB}}$ represents the main peak for $\mathrm{CB}$ in all mixtures; $\mathrm{P}_{\mathrm{CB}}^{\prime}$ indicates the shoulder peaks, which were appearing after the addition of $\mathrm{CO}$ in $\mathrm{CB}$. Similarly, $\mathrm{P}_{\mathrm{CO}}$ and $\mathrm{P}^{\prime} \mathrm{CO}$ denote the main peak for $\mathrm{CO}$ and the shoulder peak in the blends, respectively.

As explained in Section 3.2.1, pure $\mathrm{CB}\left(\mathrm{X}_{\mathrm{CB}}=1\right)$ crystallized in three fractions. Likewise, for pure $\mathrm{CO}\left(\mathrm{X}_{\mathrm{CB}}=0\right)$, two crystallization exotherms were detected, in which one was a sharp peak at a lower temperature $\left(2.5^{\circ} \mathrm{C}\right)$, and the second peak overlapped with the same peak at a higher temperature $\left(7.4^{\circ} \mathrm{C}\right)$. This could be because of incomplete crystallization of different TAGs in CO with $2 \mathrm{~K} /$ minute cooling rate. If the rate of cooling decreases, there will be the possibility of complete crystallization of these short-chained mixed saturated TAGs (CLaLa, LaLaLa, LaLaM and CCLa), as they could get adequate time to arrange properly [40]. Further, up to the mixture of $\mathrm{X}_{\mathrm{CB}}=0.50$, two different fats could be clearly identified, however, for $X_{C B}=0.40$, the crystallization of all TAGs overlapped. Although it showed one main peak, there was still the existence of two shoulder peaks of HMF and LMF. For further blends, $X_{C B}$ of $0.30,0.20$ and 0.10 , the peaks are differentiated into $P_{C O}$ for $C O$ and $\mathrm{P}^{\prime} \mathrm{CO}$ for shoulder peak, which appeared after the addition of $\mathrm{CB}$.

The melting profile of these mixtures was then studied. Figure $4 \mathrm{c}$ shows the endotherm results of all the mixtures. Similar to crystallization, the shoulder peak developed after the addition of $\mathrm{CO}$ in 
$\mathrm{CB}$, however, the identification of these peaks was only possible up to $\mathrm{X}_{\mathrm{CB}}=0.70$. For 0.60 and 0.50 , the overlapping of melting peaks started to occur. For a mixture of $\mathrm{X}_{\mathrm{CB}}=0.40$, endotherm resulted in one main peak along with small shoulders. For $\mathrm{X}_{\mathrm{CB}}$ of 0.20 and $0.10, \mathrm{P}^{\prime}{ }_{\mathrm{CO}}$ indicates the shoulder peak along with $\mathrm{P}_{\mathrm{CO}}$ as a main peak in the mixtures. Hence from both crystallization and melting profile, the mixture at $\mathrm{X}_{\mathrm{CB}}=0.40$ can be described as the eutectic mixture, however, in the case of crystallization, the peak for this concentration showed a broad profile instead of a sharp peak. Hence to determine the exact concentration profile for showing a pronounced eutectic mixture and so the eutectic point, we measured three more compositions, namely $\mathrm{X}_{\mathrm{CB}}=0.34,0.35$ and 0.36 .

The crystallization and melting profiles of the above-defined mixtures are shown in Figure 5a,b. As the first melting process could not detect any thermogram because no crystallization occurred during $24 \mathrm{~h}$, the first segment results are not shown here. The crystallization profile revealed that the shoulder peaks appeared on mixtures of $\mathrm{X}_{\mathrm{CB}}=0.40,0.34$ and 0.36 (highlighted with the arrow and blue ellipse), whereas for $X_{C B}=0.35$ mixture, no specific shoulder peak was detected. However, in the case of the remelting segment, for the concentration of $0.40,0.36$ and 0.35 the peak sharpness did not show any specific change. Another observation in both crystallization and melting, was that the peak maxima were shifting towards a higher temperature as the concentration of $\mathrm{CB}$ was decreasing (shown by the dotted line). The eutectic mixture is when the mixture melts or solidifies homogeneously at one temperature, and this temperature is below the individual melting temperature. Therefore, our results of crystallization and melting together indicated that 0.35 of $\mathrm{CB}$ and 0.65 of $\mathrm{CO}$ represented a eutectic mixture, which melted at $16.7^{\circ} \mathrm{C}$. Unfortunately, we could not succeed in achieving a sharp peak in both the crystallization and melting process. The reason for such a behavior might be the mixture of different triacylglycerol in both fats, as pure Trilaurin (TL) from CO and POP from CB do not show any resemblance with the temperature profile of $\mathrm{CB} / \mathrm{CO}$ blend (refer to supplementary Figure $\mathrm{S} 3$ ). This illustrates that the cause for eutectic mixtures of $\mathrm{CB} / \mathrm{CO}$ blend was the different mixtures of triacylglycerol and not only individual TAG, which are present in a higher amount.
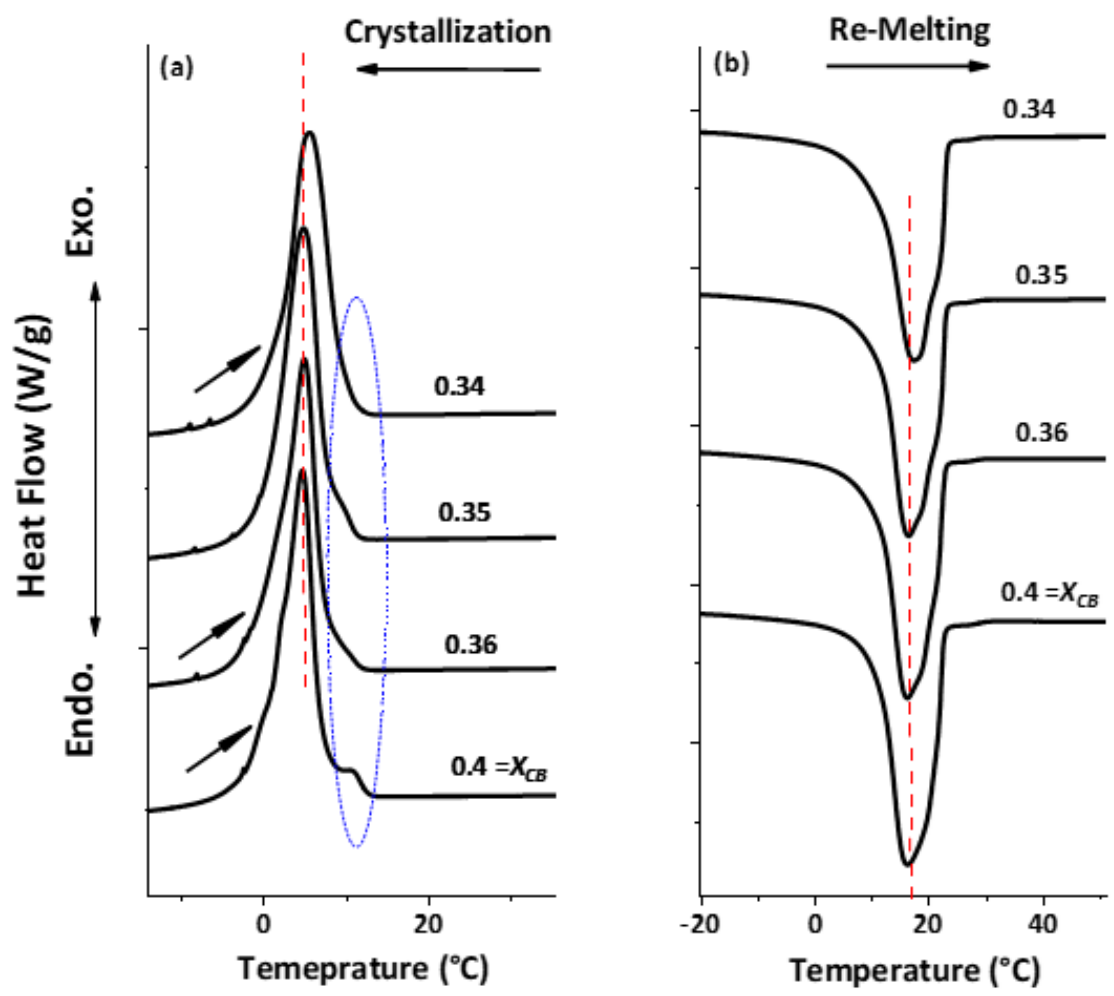

Figure 5. DSC analysis of $\mathrm{CB} / \mathrm{CO}$ blends for the determination of eutectic mixture. The samples were prepared similarly like other blends and the same process was used for DSC measurements. (a) Dynamic crystallization from $90{ }^{\circ} \mathrm{C}$ to $-50{ }^{\circ} \mathrm{C}$. (b) Remelting of crystals formed in segment (a). 
Analysis of all thermograms was plotted in Figure $6 a, b$ as enthalpy change with respect to $X_{C B}$. By using STARe software, the enthalpy change was calculated for $\mathrm{P}_{\mathrm{CB}}, \mathrm{P}_{\mathrm{CB}}^{\prime}, \mathrm{P}_{\mathrm{CO}}, \mathrm{P}_{\mathrm{CO}}$ and one $\Delta H$ value for eutectic mixtures (refer to supplementary Figures $\mathrm{S} 4$ and $\mathrm{S} 5$ ). $\Delta H$ for $\mathrm{P}_{\mathrm{CB}}$ decreased (linearly for crystallization and exponentially for melting) as the concentration of $\mathrm{CB}$ decreased in both processes, whereas, $\triangle H$ for $\mathrm{P}^{\prime} \mathrm{CB}$ increased linearly and exponentially for crystallization and melting as the concentration of $\mathrm{CB}$ decreased in the mixture, respectively. Next, for mixture 0.40 in crystallization, only one $\Delta H$ value was calculated as the addition of $\mathrm{P}_{\mathrm{CB}}$ and $\mathrm{P}_{\mathrm{CB}}^{\prime}$, similarly for melting process $0.50,0.40$ and 0.30 showed the broad peak, hence, one $\Delta H$ value was evaluated (noted as $\mathrm{P}_{\mathrm{CB}}+$ $\left.\mathrm{P}_{\mathrm{CB}}^{\prime}\right)$. In both processes, $\Delta H$ for $\mathrm{P}_{\mathrm{CO}}$ decreased as the concentration of $\mathrm{CO}$ decreased, however, $\mathrm{P}^{\prime} \mathrm{CO}$ increased as the concentration was decreased in the mixture. From these results, we can conclude that $\mathrm{P}^{\prime}{ }_{\mathrm{CB}}$ represented the $\mathrm{CO}$ phase in the blends, and $\mathrm{P}_{\mathrm{CO}}$ denoted the $\mathrm{CB}$ phase in the mixtures. Hence, from this hypothesis, one can say that there was phase separation in the case of $\mathrm{CB}$ and $\mathrm{CO}$, even if both of them had a similar melting temperature. Only the eutectic mixture showed the homogeneity in two fats.
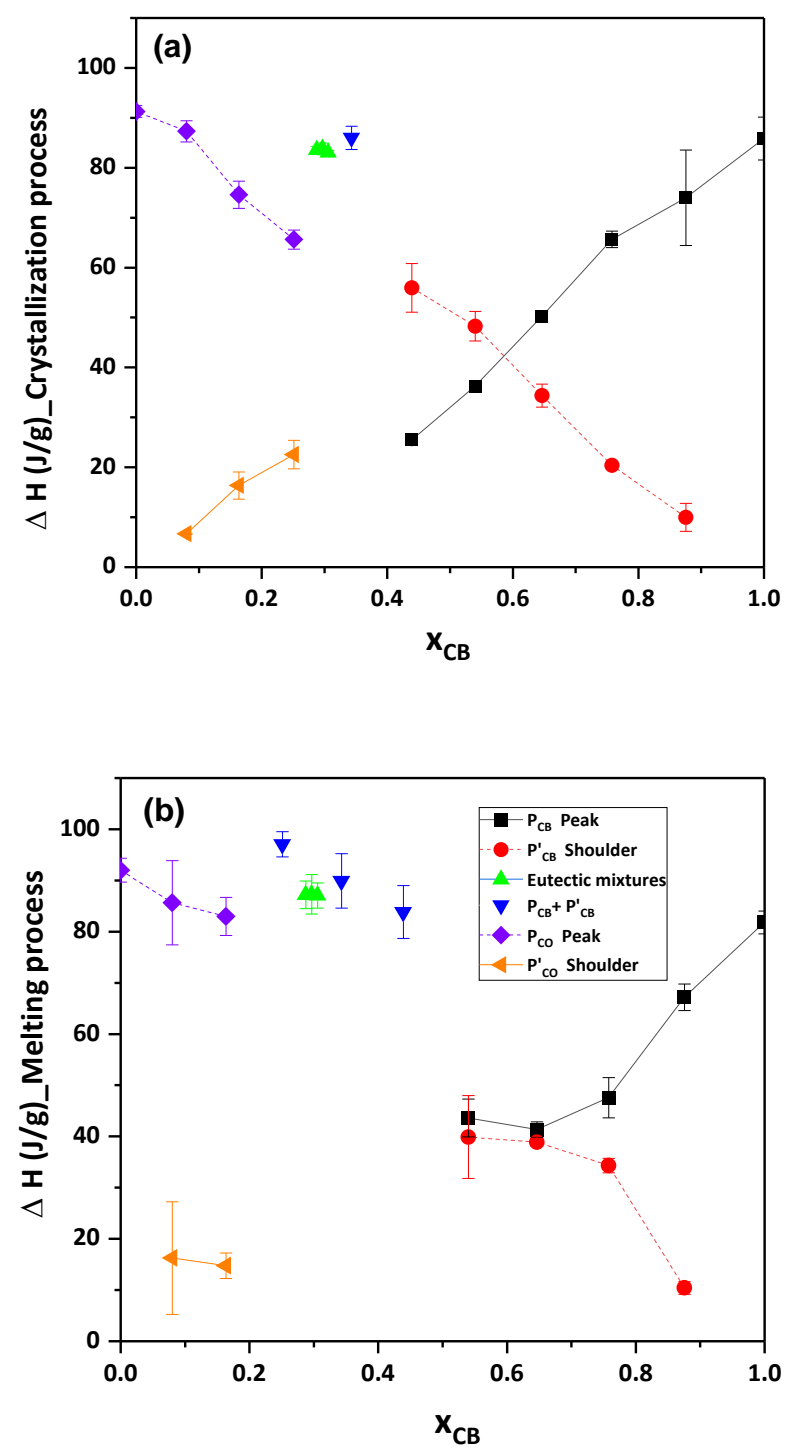

Figure 6. Enthalpy change of $\mathrm{CB}$ and $\mathrm{CO}$ during the crystallization (a) and remelting (b) process with respect to weight $\%$ of $C B$. black closed square $=\mathrm{P}_{\mathrm{CB}}$, red closed circle $=\mathrm{P}_{C B}^{\prime}$, green closed triangles $=$ eutectic mixtures $\left(\mathrm{X}_{\mathrm{CB}}=0.36,0.35,0.34\right)$, blue closed reverse triangles $=\mathrm{P}_{\mathrm{CB}}+\mathrm{P}^{\prime}{ }_{\mathrm{CB}}$, purple closed diamond $=\mathrm{P}_{\mathrm{CO}}$, orange closed diamonds $=\mathrm{P}^{\prime} \mathrm{CO}$. 


\subsection{Pseudophase Diagram Comparison between CB/TS and CB/CO System}

The solid-liquid phase diagram for $\mathrm{CB} / \mathrm{TS}$ and $\mathrm{CB} / \mathrm{CO}$ was plotted by using DSC data from the remelting segment with respect to the mole fraction $\left(x_{C B}\right)$ in Figure $7 \mathrm{a}, \mathrm{b}$. In Figure $7 \mathrm{a}$, the horizontal line (solidus line) achieved from onset point $\left(\mathrm{P}_{\mathrm{CB}}\right)$ and the monotonously increasing line (liquidus line) plotted from the melting profile of $\left(\mathrm{P}_{\mathrm{TS}}\right)$ described that the two fats were completely immiscible with each other. This solid-liquid phase diagram exhibits a monotectic behavior [41] where the solidus line occurs as a horizontal and the liquidus line increases from the melting temperature of pure $C B$ to pure TS. The phase diagram shows that below the solidus line, solids of $\mathrm{TS}\left(\mathrm{S}_{\mathrm{TS}}\right)$ and $\mathrm{CB}\left(\mathrm{S}_{\mathrm{CB}}\right)$ coexist. However, at $x_{C B}=0$ the $S_{T S}$ exists until $\alpha$ form melt. Above the solidus line, liquids of $C B\left(\mathrm{~L}_{\mathrm{CB}}\right)$ and $\mathrm{S}_{\mathrm{TS}}$ coexist until the S-L-S transition line. At this transition line, liquid transformed into solids of TS, and then the melting started. Hence, above this transition line, $\mathrm{L}_{\mathrm{CB}}$, partial liquid of TS along with solids of TS coexisted. Above the liquidus line, both of the components were present in the liquid phase. A similar phase diagram was obtained in the case of POP/PPP mixtures [42]. According to their study, the phase diagram (POP/PPP) indicated that the interaction between monounsaturated (Sat-U-Sat) TAG and TAG of monosaturated fatty acid (PPP) could behave as a monotectic partial solid solution (as the difference in melting temperature of the TAG component is more). Therefore, our results agreed with their findings and it might be in the case of $C B$ and TS that the mixture behaves as a monotectic partial solid solution.
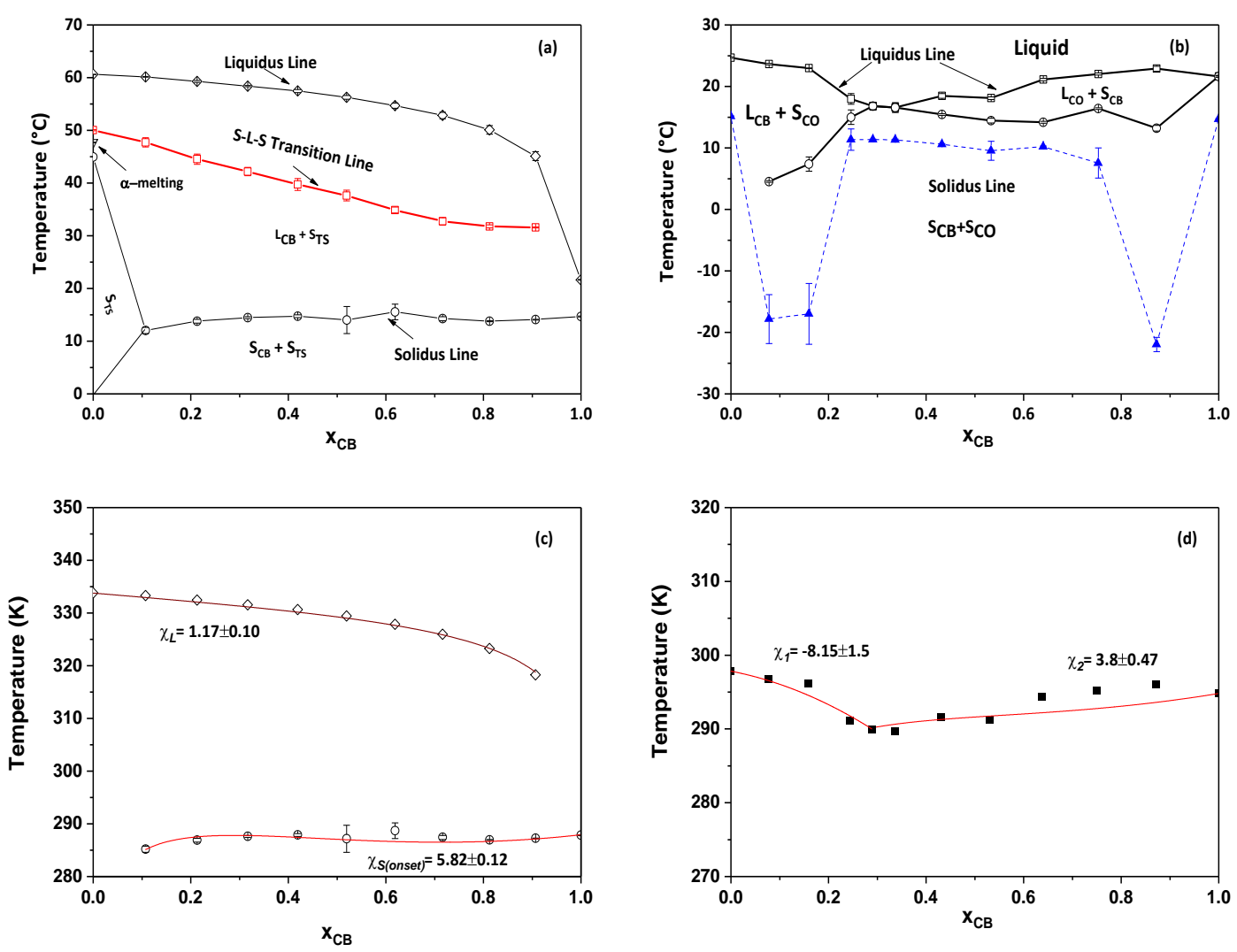

Figure 7. Comparison between pseudophase diagrams of (a) $\mathrm{CB} / \mathrm{TS}$ blends (b) $\mathrm{CB} / \mathrm{CO}$ blends. $\mathrm{CB} / \mathrm{TS}$ phase diagram depicts a monotectic mixture of $\mathrm{CB} / \mathrm{TS}$, whereas $\mathrm{CB} / \mathrm{CO}$ shows a eutectic mixture at $\mathrm{X}_{\mathrm{CB}}$ $=0.35$. $(\mathbf{c}, \mathbf{d})$ represents the fitting of phase diagram by using Bragg-Williams approximation for CB/TS and $\mathrm{CB} / \mathrm{CO}$ blends, respectively.

Likewise, Figure $7 \mathrm{~b}$ shows the solid-liquid phase diagram plotted for $\mathrm{CB} / \mathrm{CO}$ blends from the DSC result. The liquidus line was constructed by considering peak temperature $\left(\mathrm{P}_{\mathrm{CB}}\right.$ and $\mathrm{P}_{\mathrm{CO}}$ in Figures $4 c$ and $5 b$ ) in all blends, and the solidus line was achieved from onset temperature (blue 
triangles) and shoulder peak temperature $\left(\mathrm{P}_{\mathrm{CB}}^{\prime}\right.$ and $\mathrm{P}_{\mathrm{CO}}^{\prime}$ in Figures $4 \mathrm{c}$ and $\left.5 \mathrm{~b}\right)$. Up to the solidus line, both components were in solid phases and above the solidus line from composition $\mathrm{X}_{\mathrm{CB}}=0.35$ to 1 , liquid of $\mathrm{CO}\left(\mathrm{L}_{\mathrm{CO}}\right)$ and solid of $\mathrm{CB}\left(\mathrm{S}_{\mathrm{CB}}\right)$ coexisted, whereas, for composition range of $\mathrm{X}_{\mathrm{CB}}=0$ to 0.35 , liquid of $\mathrm{CB}\left(\mathrm{L}_{\mathrm{CB}}\right)$ and solid-state of $\mathrm{CO}\left(\mathrm{S}_{\mathrm{CO}}\right)$ coexisted. Above the liquidus line, both components were in the liquid phase.

The thermodynamic analysis of the liquidus and solidus line was performed by assuming nonideal mixing in both liquid and solid phases. Hence, Bragg-Williams approximation was considered instead of the Hildebrand model, which describes the ideal mixing behavior. In the present study of the $\mathrm{CB} / \mathrm{TS}$ phase diagram, component $A$ represents $T S$ and component $B$ is $C B$, whereas, in the $C B / C O$ system, A denotes $C B$ and B is CO. The fitting of Bragg-Williams approximation is shown in Figure $7 c, d$. Hence for fitting the liquidus line data for the CB/TS system, we used Equation (4) with the values of $\Delta H_{T S}=118,387.8 \mathrm{~J} / \mathrm{mol}, T_{T S}=333.76 \mathrm{~K}$ and $R$ as $8.314 \mathrm{~J} / \mathrm{K} . \mathrm{mol}$. Similarly for fitting the solidus line, we have considered Equation (5) with values of $\Delta H_{C B}=66,498.3 \mathrm{~J} / \mathrm{mol}$ and $T_{C B}=294.785 \mathrm{~K}$. For fitting the solidus line, we considered the onset temperature. After fitting the experimental data, $\chi_{L}$ value was calculated as $1.17+0.10 \mathrm{~kJ} / \mathrm{mol}\left(R^{2}>0.98\right)$ and $\chi_{s}$ (onset) as $5.82 \pm 0.12 \mathrm{~kJ} / \mathrm{mol}\left(R^{2}>0.57\right)$ respectively. These high positive values indicated that the interaction energy of the CB-TS pair was more than the average of the CB-CB and TS-TS pair. This result suggests that some repulsive interaction acts between CB-TS, hence the energy needed is more. As a result, CB and TS are completely immiscible with each other in the solid phase. The possible reason for the higher interaction energy in CB-TS could be the structures of TAGs in CB and TS. Due to the presence of the oleic acid in the CB structure, the chain packing becomes complex in nature. Therefore, TS could have encountered difficulty in arranging themselves in a closely packed manner, whereas, in the case of mixing two TAGs with at least one unsaturated fatty acid (in both of them), there could be less difficulties to pack themselves closer [8]. Hence, in the case of CB/TS blends, CB could act as an impurity, and this might lead to a decrease in the temperature of TS as the concentration of CB increased in it. Similar results were also obtained by the study of oleic acid and stearic acid mixtures, where the stearic acid temperature decreased after the addition of oleic acid; however, there was no change in two polymorphs ( $\alpha$ and $\gamma$ ) of oleic acid's temperature profile [25].

For thermodynamic analysis of the $\mathrm{CB} / \mathrm{CO}$ phase diagram, Equations (4) and (5) were used from the composition range of $x_{E} \leq x_{C B} \leq 1$ and $0 \leq x_{C B} \leq x_{E}$ respectively. Hence, the values of $\Delta H_{C B}=66,498.3 \mathrm{~J} / \mathrm{mol}, T_{C B}=294.785 \mathrm{~K}, \Delta H_{C O}=57,217.78 \mathrm{~J} / \mathrm{mol}, T_{C O}=297.815 \mathrm{~K}$ were considered from DSC results for fitting the experimental data. The fitting of the liquidus line is shown in Figure $7 \mathrm{~d}$. According to investigations by Abes et al., for binary mixtures of saturated fatty acids (SS/MM), the interaction parameter gave only one value for whole composition range [26]. However, in our studies, for composition range from 0 to $0.35 \mathrm{wt} \%$ of $C B$, the value of $\chi$ was $-8.15 \pm 1.15 \mathrm{~kJ} / \mathrm{mol}$ $\left(R^{2}>0.54\right)$ and for the other range was $3.8 \pm 0.47 \mathrm{~kJ} / \mathrm{mol}\left(R^{2}>0.59\right)$. Due to differences in molecular structure and its volume, this approximation is not very well suited for $\mathrm{CB} / \mathrm{CO}$ blends. From these values, it can be described that for $\mathrm{CO}$ and mixture with $\mathrm{CB}, \mathrm{CB}-\mathrm{CO}$ pair is more compatible than $\mathrm{CB}-\mathrm{CB}$ pair and $\mathrm{CO}-\mathrm{CO}$ pair in the liquid phase. For $\mathrm{CB} / \mathrm{CO}$ blends of composition range from $\mathrm{X}_{\mathrm{CB}}=0.35$ to 1 , the large positive value, lead to the hypothesis that $\mathrm{CB}-\mathrm{CO}$ interaction energy is more and hence there is phase separation in the liquid phase; the reason for such behavior is their molecular structure. CB has monounsaturated TAGs, and because of oleic acid, the molecular length is reduced due to a kink of the double bond, and hence, the molecular length of $\mathrm{CB}$ and $\mathrm{CO}$ becomes similar to each other and thus leads to the CB-CO pair instead of like pairs. In the case of further composition from eutectic to 1 , an arrangement of $\mathrm{CO}$, having a mixture of short chained $(\mathrm{C} 12, \mathrm{C} 10$ and C8) saturated TAGs and CB as monounsaturated TAGs, could not pack densely due to presence of a high percentage of $\mathrm{CB}$, which is not flexible in nature even, in a liquid state.

Although Bragg-Williams type approximations used in our study for understanding the phenomenological interaction between $\mathrm{CB} / \mathrm{TS}$ and $\mathrm{CB} / \mathrm{CO}$ blends and the results obtained were in agreement with DSC results, it is still unclear how these interactions specifically take place in 
such complex fat/oil mixtures. A precise molecular interpretation is difficult, since, in the original Bragg-Williams approach, the interaction parameters were defined by pseudopotentials between monomers only. In the mixtures of the fatty acids, most of the monomers are identical, i.e., carbon-carbon bond and esterified glycerol bond. The main difference of the energy mismatch has its origin in the appearing cis-double bonds and the different chain lengths of the fatty acids. Both cause a large number of "defects" in the different polymorphs, which cause a major contribution to the energy balance. Hence, the Bragg-Williams model can be considered, in general, only as a phenomenological model to describe the phase diagrams for fat blends.

Nevertheless, the fitting results lead to the prediction that such interactions could occur due to either aliphatic chain packing, of which several forms exist, and/or the difference in carbonyl group conformational changes [24]. Hence, precise pinpointing of the interaction causing such behavior in both of our systems is challenging. Additionally, according to our data, we can say that this approximation does not take into consideration the various polymorphic states that exist in several other systems used in such studies, and hence makes it rather difficult to comprehend the interactions between distinct fat/oil blends.

\subsection{Morphological Studies of $C B / T S$ and $C B / C O$}

The crystal morphology of $\mathrm{CB} / \mathrm{TS}$ and $\mathrm{CB} / \mathrm{CO}$ blends has been captured by PLM. Figure 8 shows the crystal morphology of pure $\mathrm{CB}, \mathrm{CO}$ and TS after $24 \mathrm{~h}$ at $22{ }^{\circ} \mathrm{C}$ and after heating this sample to $90^{\circ} \mathrm{C}$ and cooling down to $10^{\circ} \mathrm{C}$ with $2 \mathrm{~K} /$ minute rate.

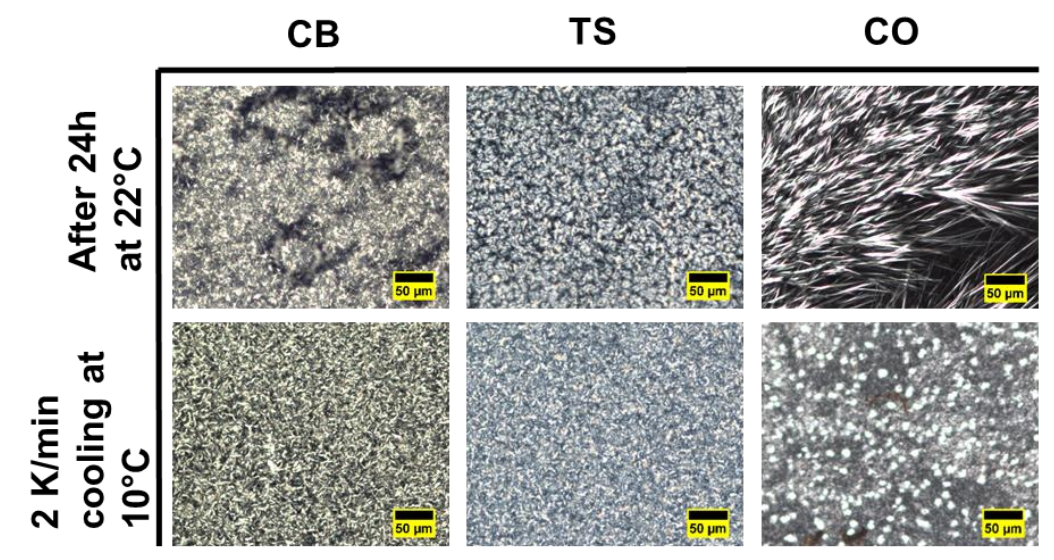

Figure 8. PLM analysis of pure fats after isothermal crystallization at $22{ }^{\circ} \mathrm{C}$ for $24 \mathrm{~h}$ and dynamic crystallization at $10^{\circ} \mathrm{C}$ by cooling down with $2 \mathrm{~K} /$ minute rate. Scale bar $=50 \mu \mathrm{m}$.

The pictures captured after $24 \mathrm{~h}$ at $22{ }^{\circ} \mathrm{C}$, show the crystal formation after the isothermal crystallization process; hence, one can understand the morphology of the crystals, which were melted during the DSC melting segment (Figures 2a and 4a). According to DSC results, for pure CB, the mixture of form IV $\left(\beta_{1}{ }^{\prime}\right)$ and form V $\left(\beta_{2}\right)$ was formed after $24 \mathrm{~h}$ at $22^{\circ} \mathrm{C}$, and the visualization of these polymorphs can be viewed in Figure 8. The morphology can be described as a high number of small size crystallites along with some spherulites having a needle-like structure at the periphery. In the case of pure TS, a spherulitic crystal network was formed. For pure $\mathrm{CO}$, a sharp needle structure was observed at $22^{\circ} \mathrm{C}$; however, in the case of DSC, no sharp melting was observed.

After heating at $90^{\circ} \mathrm{C}$ and cooling down to $10^{\circ} \mathrm{C}$, the formation of crystal morphology shows the visualization of the crystallization process from DSC (Figures $2 b$ and $4 b$ ). In Figure 8 , for all pure components, the crystal size changed to smaller and denser as compared to isothermal crystallization. In the case of Pure CB, the crystals are the aggregation of small needles, and pure TS showed very small grainy structures. Similarly, for pure $\mathrm{CO}$, the combination of small denser spheres and granular structure were formed. 
Furthermore, the effect of the addition of different fats on the crystal morphology of pure CB was further studied. Figure 9a shows the changes in crystal morphology after the addition of TS in CB for isothermal and dynamic crystallization. For $X_{C B}$ of 0.90 and 0.80 , at $22^{\circ} \mathrm{C}$ after $24 \mathrm{~h}$, spherulites consisting of needles were observed. For further compositions, the size of the spherulitic aggregates of needles was decreased as the concentration of TS increased. For dynamic crystallization, after the addition of TS in CB, crystal size reduced and formed the grainy structure for the composition of 0.90 and 0.80 . From 0.70 to 0.30 of $C B$, the mixture of small spherulitic crystal structure and the grainy structure was observed. Again, for further compositions, smaller crystals were formed as the concentration of TS increased.

(a) $\mathrm{CB} / \mathrm{TS}$

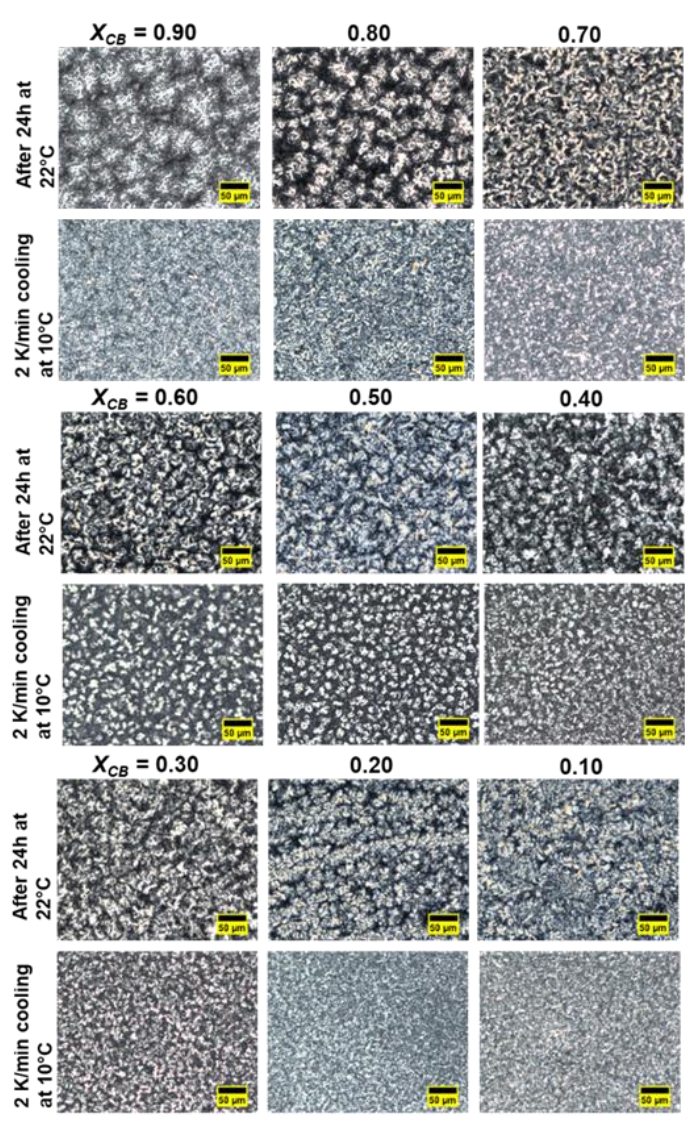

(b) $\mathrm{CB} / \mathrm{CO}$

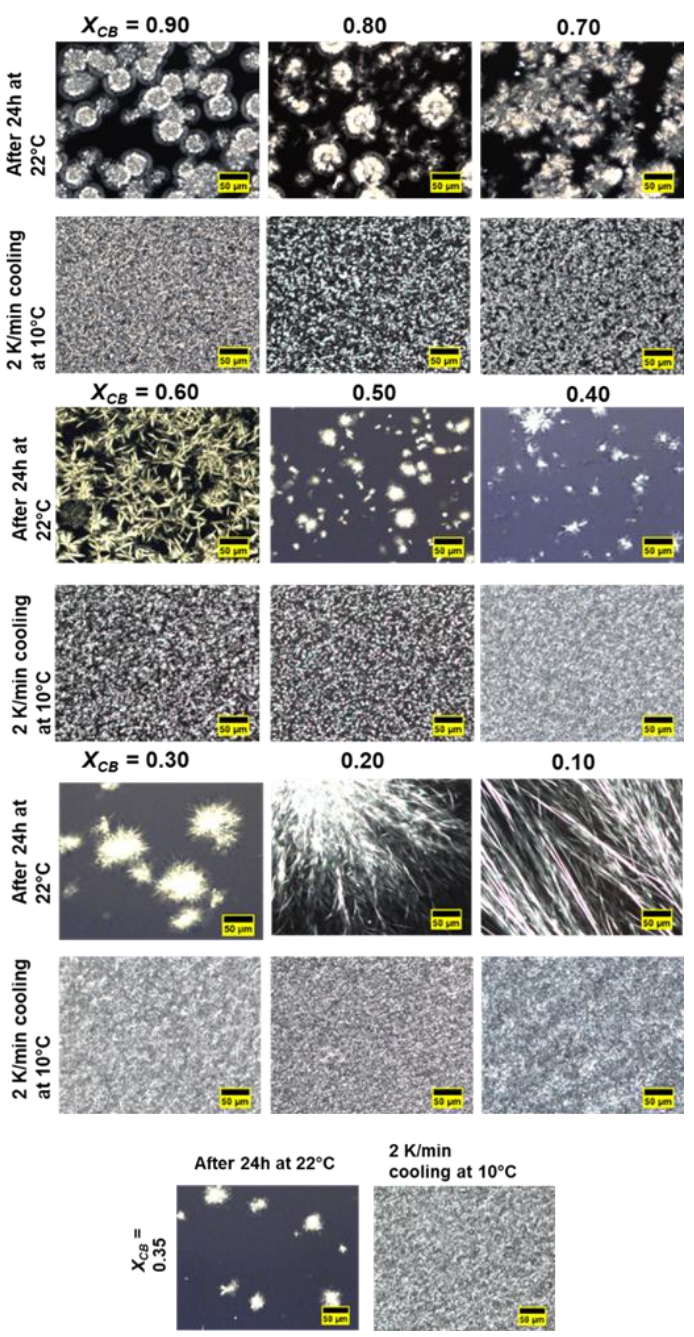

Figure 9. PLM analysis of (a) CB/TS blends, and (b) CB/CO blends after crystallizing isothermally at $22{ }^{\circ} \mathrm{C}$ for $24 \mathrm{~h}$ and then heating the sample to $90{ }^{\circ} \mathrm{C}$ and cooled down to $10{ }^{\circ} \mathrm{C}$ with $2 \mathrm{~K} / \mathrm{min}$ rate for studying the effect of dynamic crystallization. Scale bar $=50 \mu \mathrm{m}$.

In contrast to $\mathrm{CB} / \mathrm{TS}$ blends, a mixture of $\mathrm{CB}$ and $\mathrm{CO}$ showed various changes in crystal morphology depending on the $\mathrm{CO}$ concentration after $24 \mathrm{~h}$. For $\mathrm{X}_{\mathrm{CB}}=0.90$, spherulitic morphology was observed, likewise for 0.80 and 0.70 also showed the combination of a needlelike and spherulitic crystal nature. However, at 0.60 , more sharp needles were viewed as compared to spherulitic. For 0.50 and 0.60 compositions, the size of spherulites was reduced, as was the amount of crystallinity of the whole sample blend. As the concentration of CO increased further, more sharp, needlelike crystal morphology 
was captured. After dynamic crystallization, the size of crystallites decreased drastically which is in agreement with the $\mathrm{CB} / \mathrm{TS}$ results.

\section{Summary}

This study focused on the mixing behavior in $\mathrm{CB} / \mathrm{TS}$ and $\mathrm{CB} / \mathrm{CO}$ mixtures in different phases, on the basis of the solid-liquid phase diagram. DSC results depicted that $\mathrm{CB} / \mathrm{TS}$ mixtures were completely immiscible in the solid phase and well mixed in a liquid state, whereas $\mathrm{CB} / \mathrm{CO}$ showed eutectic mixture at $65 \mathrm{wt} \%$ of $\mathrm{CO}$ and $35 \mathrm{wt} \%$ of CB. Similarly, the thermodynamic analysis of the phase diagram resulted in: (1) the interaction for the mixed pair of $\mathrm{CB} / \mathrm{TS}$ was energetically much more unfavorable than $\mathrm{CB}-\mathrm{CB}$ and TS-TS pair; (2) in the case of $\mathrm{CB} / \mathrm{CO}$, the interaction of a mixed pair was favorable from $100 \mathrm{wt} \% \mathrm{CO}$ to $\mathrm{E}_{\mathrm{CB}-\mathrm{CO}}$ (eutectic mixture) and unfavorable from $\mathrm{E}_{\mathrm{CB}-\mathrm{CO}}$ to $100 \mathrm{wt} \% \mathrm{CB}$.

Isothermal and dynamic crystallization processes altered the thermal properties and crystal morphology of $\mathrm{CB} / \mathrm{TS}$ and $\mathrm{CB} / \mathrm{CO}$ blends. From our results of the dynamic crystallization process, we can say that a decrease in melting temperature results in small granular crystal morphology of blends, whereas in isothermal crystallization, spherulitic to needlelike structures were formed that resulted in higher melting points. Thus we can conclude that the variations in thermal and morphological behavior of fat and oil ( $\mathrm{CB} / \mathrm{TS}$ and $\mathrm{CB} / \mathrm{CO}$ ) blends are highly dependent on: (1) crystallization kinetics, and (2) "defects" created in crystal structure arrangements due to monounsaturated part of CB.

To summarize, these results improve the understanding of molecular interactions in bulk fat-fat and fat-oil systems, as well as helping to explain the different thermal behaviors of various such mixtures. From an application point of view, this will ultimately help to engineer new types of fat-based products with desired properties, such as different organoleptic characteristics, which can be related to different mixing ratios.

Supplementary Materials: The following are available online at http://www.mdpi.com/2304-8158/9/3/327/s1, Figure S1: Area under the peaks for CB (50\%)+TS (50\%) is shown, Section 2: Supplementary reasoning for Section 3.2.1, Figure S2: SFC of $\mathrm{CB} / \mathrm{CO}$ blends at $22^{\circ} \mathrm{C}$ after $24 \mathrm{~h}$ showed eutectic behavior, Figure S3: The DSC thermogram for pure components of $\mathrm{CB}(\mathrm{POP})$ and $\mathrm{CO}$ (Trilaurin) showed no eutectic behavior, Figure S4: Area under the curves for $\mathrm{P}_{\mathrm{CO}}$ and $\mathrm{P}^{\prime} \mathrm{CO}$ for $\mathrm{CB}(10 \%)+\mathrm{CO}(90 \%)$, Figure S5: Area under the curves for $\mathrm{P}_{\mathrm{CB}}$ and $\mathrm{P}_{\mathrm{CB}}^{\prime}$ for $\mathrm{CB}(90 \%)+\mathrm{CO}(10 \%)$.

Author Contributions: Conceptualization, B.L.J., B.I.Z. and T.A.V.; Methodology, B.L.J. and B.I.Z.; Software, B.L.J.; Validation, B.L.J., B.I.Z. and T.A.V.; Formal analysis, B.L.J., B.I.Z. and T.A.V.; Investigation, B.L.J.; Data curation, B.L.J.; Writing-original draft preparation, B.L.J.; Writing—review and editing, B.I.Z. and T.A.V.; Visualization, B.L.J. and T.A.V.; Supervision, T.A.V.; Project administration, T.A.V.; All authors have read and agreed to the published version of the manuscript.

Funding: This research received no external funding.

Acknowledgments: The authors would like to thank Petra Räder and Robert Graf for providing support during DSC and NMR experiments. Also thankful to MPIP soft matter and food science group for helpful discussions especially Sarah Gindra.

Conflicts of Interest: The authors declare no conflict of interest.

\section{References}

1. Abdulkarim, S.M.; Myat, M.W.; Ghazali, H.; Roselina, K.; Abbas, K. Sensory and Physicochemical Qualities of Palm Olein and Sesame Seed Oil Blends during Frying of Banana Chips. J. Agric. Sci. 2014, 2, 18-29. [CrossRef]

2. Berdick, M. The role of fats and oils in cosmetics. J. Am. Oil Chem. Soc. 1972, 49, 406-408. [CrossRef] [PubMed]

3. Tenjarla, S. Microemulsions: An overview and pharmaceutical applications. Crit. Rev. Ther. Drug Carr. Syst. 1999, 16, 62. [CrossRef]

4. Lonchampt, P.; Hartel, R.W. Fat bloom in chocolate and compound coatings. Eur. J. Lipid Sci. Technol. 2004, 106, 241-274. [CrossRef] 
5. Loisel, C.; Lecq, G.; Keller, G.; Ollivon, M. Dynamic Crystallization of Dark Chocolate as Affected by Temperature and Lipid Additives. J. Food Sci. 2006, 63, 73-79. [CrossRef]

6. Vilgis, T.A. Soft matter food physics-The physics of food and cooking. Rep. Prog. Phys. 2015, 78, 124602. [CrossRef] [PubMed]

7. Larsson, K. Classification of glyceride crystal forms. Acta Chem. Scand 1966, 20, 2255-2260. [CrossRef]

8. Himawan, C.; Starov, V.M.; Stapley, A.G.F. Thermodynamic and kinetic aspects of fat crystallization. Adv. Colloid Interface Sci. 2006, 122, 3-33. [CrossRef]

9. Rossell, J.B. Phase diagrams of triglyceride systems. In Advances in Lipid Research; Elsevier: Amsterdam, The Netherlands, 1967; Volume 5, pp. 353-408.

10. Bouzidi, L.; Narine, S.S. Relationships between molecular structure and kinetic and thermodynamic controls in lipid systems. Part II: Phase behavior and transformation paths of SSS, PSS and PPS saturated triacylglycerols-Effect of chain length mismatch. Chem. Phys. Lipids 2012, 165, 77-88. [CrossRef] [PubMed]

11. Liu, C.; Meng, Z.; Cao, P.; Jiang, J.; Liang, X.; Piatko, M.; Campbell, S.; Lo, S.K.; Liu, Y. Visualized phase behavior of binary blends of coconut oil and palm stearin. Food Chem. 2018, 266, 66-72. [CrossRef]

12. Loisel, C.; Keller, G.; Lecq, G.; Bourgaux, C.; Ollivon, M. Phase transitions and polymorphism of cocoa butter. J. Am. Oil Chem. Soc. 1998, 75, 425-439. [CrossRef]

13. Wille, R.L.; Lutton, E.S. Polymorphism of cocoa butter. J. Am. Oil Chem. Soc. 1966, 43, 491-496. [CrossRef] [PubMed]

14. Windbergs, M.; Strachan, C.J.; Kleinebudde, P. Investigating the Principles of Recrystallization from Glyceride Melts. AAPS PharmSciTech 2009, 10, 1224-1233. [CrossRef] [PubMed]

15. Campos, R.; Ollivon, M.; Marangoni, A.G. Molecular composition dynamics and structure of cocoa butter. Cryst. Growth Des. 2010, 10, 205-217. [CrossRef]

16. Lipp, M.; Anklam, E. Review of cocoa butter and alternative fats for use in chocolate-part A. Compositional data. Food Chem. 1998, 62, 73-97. [CrossRef]

17. Lipp, M.; Anklam, E. Review of cocoa butter and alternative fats for use in chocolate-Part B. Analytical approaches for identification and determination. Food Chem. 1998, 62, 99-108. [CrossRef]

18. Rothkopf, I.; Danzl, W. Changes in chocolate crystallization are influenced by type and amount of introduced filling lipids. Eur. J. lipid Sci. Technol. 2015, 117, 1714-1721. [CrossRef]

19. Geary, M.; Hartel, R. Crystallization Behavior and Kinetics of Chocolate-Lauric Fat Blends and Model Systems. JAOCS J. Am. Oil Chem. Soc. 2017, 94, 683-692. [CrossRef]

20. Williams, S.D.; Ransom-Painter, K.L.; Hartel, R.W. Mixtures of palm kernel oil with cocoa butter and milk fat in compound coatings. J. Am. Oil Chem. Soc. 1997, 74, 357-366. [CrossRef]

21. Quast, L.B.; Luccas, V.; Ribeiro, A.P.B.; Cardoso, L.P.; Kieckbusch, T.G. Physical properties of tempered mixtures of cocoa butter, CBR and CBS fats. Int. J. Food Sci. Technol. 2013, 48, 1579-1588. [CrossRef]

22. Ali, A.R.M.; Dimick, P.S. Melting and solidification characteristics of confectionery fats: Anhydrous milk fat, cocoa butter and palm kernel stearin blends. J. Am. Oil Chem. Soc. 1994, 71, 803-806. [CrossRef]

23. Timms, R.E. Phase behaviour of fats and their mixtures. Prog. Lipid Res. 1984, 23, 1-38. [CrossRef]

24. Sato, K. Crystallization of Lipids; John Wiley \& Sons Ltd.: Hoboken, NJ, USA, 2018; pp. 17-60.

25. Inoue, T.; Hisatsugu, Y.; Yamamoto, R.; Suzuki, M. Solid-liquid phase behavior of binary fatty acid mixtures: 1. Oleic acid/stearic acid and oleic acid/behenic acid mixtures. Chem. Phys. Lipids 2004, 127, $143-152$. [CrossRef] [PubMed]

26. Abes, M.; Bouzidi, L.; Narine, S.S. Crystallization and phase behavior of 1,3-propanediol esters: II. 1,3-Propanediol distearate/1,3-propanediol dipalmitate (SS/PP) and 1,3-propanediol distearate/1,3propanediol dimyristate (SS/MM) binary systems. Chem. Phys. Lipids 2007, 150, 89-108. [CrossRef]

27. Brumbaugh, E.E.; Johnson, M.L.; Huang, C. Non-linear least squares analysis of phase diagrams for non-ideal binary mixtures of phospholipids. Chem. Phys. Lipids 1990, 52, 69-78. [CrossRef]

28. Lee, A.G. Lipid phase transitions and phase diagrams II. Mixtures involving lipids. BBA Rev. Biomembr. 1997, 472, 285-344. [CrossRef]

29. Tenchov, B.G. Nonuniform lipid distribution in membranes. Prog. Surf. Sci. 1985, 20, 273-340. [CrossRef]

30. Flory, P.J. Principles of Polymer Chemistry; Cornell University Press: Ithaca, NY, USA, 1953.

31. Reyes-Hernández, J.; Dibildox-Alvarado, E.; Charó-Alonso, M.A.; Toro-Vazquez, J.F. Physicochemical and rheological properties of crystallized blends containing trans-free and partially hydrogenated soybean oil. JAOCS J. Am. Oil Chem. Soc. 2007, 84, 1081-1093. [CrossRef] 
32. Brunello, N.; McGauley, S.E.; Marangoni, A. Mechanical properties of cocoa butter in relation to its crystallization behavior and microstructure. LWT Food Sci. Technol. 2003, 36, 525-532. [CrossRef]

33. Mattson, F.H.; Volpenhein, A. The specific distribution of fatty acids in the glycerides of vegetable fats. Order 1961, 236, 2.

34. Davis, T.R.; Dimick, P.S. Lipid composition of high-melting seed crystals formed during cocoa butter solidification. J. Am. Oil Chem. Soc. 1989, 66, 1494-1498. [CrossRef]

35. Marty, S.; Marangoni, A.G. Effects of cocoa butter origin, tempering procedure, and structure on oil migration kinetics. Cryst. Growth Des. 2009, 9, 4415-4423. [CrossRef]

36. Toro-Vazquez, J.F.; Pérez-Martínez, D.; Dibildox-Alvarado, E.; Charó-Alonso, M.; Reyes-Hernández, J. Rheometry and Polymorphism of Cocoa Butter During Crystallization Under Static and Stirring Conditions. JAOCS J. Am. Oil Chem. Soc. 2004, 81, 195-202. [CrossRef]

37. Pérez-Martínez, D.; Alvarez-Salas, C.; Morales-Rueda, J.A.; Toro-Vazquez, J.F.; Charó-Alonso, M.; Dibildox-Alvarado, E. The effect of supercooling on crystallization of cocoa butter-vegetable oil blends. J. Am. Oil Chem. Soc. 2005, 82, 471-479. [CrossRef]

38. Lavigne, F.; Bourgaux, C.; Ollivon, M. Phase transitions of saturated triglycerides. J. Phys. IV Colloq. 1993, 3, 137-140. [CrossRef]

39. Garti, N.; Sato, K. Crystallization and Polymorphism of Fats and Fatty Acids-Surfactance Science Series; M. Dekker Inc.: New York, NY, USA, 1988.

40. Tan, C.P.; Man, Y.B.C. Differential scanning calorimetric analysis of palm oil, palm oil based products and coconut oil: Effects of scanning rate variation. Food Chem. 2002, 76, 89-102. [CrossRef]

41. Small, D.M. The physical chemistry of lipids from alkanes to phospholipids. Handb. Lipid Res. 1986, 4, 1-672.

42. Bruin, S. Phase equilibria for food product and process design1. Fluid Phase Equilib. 1999, 158, 657-671. [CrossRef]

(C) 2020 by the authors. Licensee MDPI, Basel, Switzerland. This article is an open access article distributed under the terms and conditions of the Creative Commons Attribution (CC BY) license (http://creativecommons.org/licenses/by/4.0/). 